\title{
Produção e disseminação de informação tecnológica: a atuação da Inova - Agência de Inovação da UNICAMP
}

\author{
Production and dissemination of technological information: \\ the performance of Inova - Agency of Innovation of the \\ UNICAMP
}

Alexandre Camargo CASTRO'

Celeste Aída Sirotheau Corrêa JANNUZZI²

Fernando Augusto Mansor de MATTOS 3

\section{RESUMO}

Este trabalho procura demonstrar como a Inova-Unicamp - Agência de Inovação da UNICAMP - produz e dissemina as informações tecnológicas geradas a partir dos produtos de conhecimento criados na Universidade e que proporcionam as condições para a inovação, e em que medida se pode considerá-la como um modelo a ser implementado em contextos similares.

Palavras-chave: informação tecnológica; inovação; produção e disseminação de informação tecnológica.

ABSTRACT

This work aims to demonstrate how Inova-Unicamp - Agency for Innovation of UNICAMP - produces and disseminates the technological information generated from the knowledge products created at the University and which provide conditions for the innovation, and whether we can consider it as a model to be implemented in similar contexts.

Keywords: technological information; innovation; production and dissemination of technological information.

\section{INTROD UÇÃO}

De valor inestimável para a sociedade em geral, o conhecimento apresenta-se hoje com uma produção cada vez mais crescente. Como conseqüência natural dessa realidade, o volume de informações também cresce de forma geométrica.

Dos diferentes tipos de informações geradas pela sociedade, destaca-se a informação científica e

\footnotetext{
1 Mestre em Ciência da Informação, Professor, Faculdade de Administração, Faculdades Network. Av. Ampélio Gazzetta, 2445, Lopes Iglesias, 13460-000, Nova Odessa, SP, Brasil. Correspondência para/Correspondence to: A.C. CASTRO. E-mail: <alexandrecmail@yahoo.com.br>.

2 Professora Doutora, Centro de Economia e Administração, Pontifícia Universidade Católica de Campinas. Rod. Dom Pedro I, Km 136, Parque das Universidades, 13086-900, Campinas, SP, Brasil. E-mail: <celeste.jannuzzi@puc-campinas.edu.br>.

3 Professor Doutor, Centro de Ciências Sociais Aplicadas, Programa de Pós-graduação em Ciência da Informação, Pontifícia Universidade Católica de Campinas. Rua Marechal Deodoro, 1099, Centro, 13010-920, Campinas, SP, Brasil. E-mail:

<fermatt@uol.com.br>.

Recebido em 6/11/2006 e aceito para publicação em 12/3/2007
} 
tecnológica pelo seu importante papel no desenvolvimento de uma nação. A informação produzida pela ciência e traduzida em tecnologia é fundamental para a competitividade em função da inovação que pode alavancar.

O processo de inovar depende inequivocamente da disponibilidade de informação, portanto a produção e disseminação da informação, como elementos fundamentais para gerar inovação, fazem parte dos recursos estratégicos da economia de um país.

Frente às informações geradas e o seu uso ainda incipiente é que se dá a discussão de como organizar a produção e realizar a disseminação de informação no Brasil.

É nesse contexto que as universidades brasileiras revelam sua importante função como responsáveis em grande parte - pela geração da informação científica e tecnológica. Entretanto, apesar da produção crescente de conhecimentos científicos e tecnológicos e do valor da informação como geradora de novos conhecimentos, observa-se que no Brasil ainda se faz pouco uso desses recursos como fatores determinantes para atuar de forma inovadora no mercado.

Objetivo deste artigo é apresentar os resultados do estudo de caso realizado na Inova - Agência de Inovação da Unicamp. Por meio da análise da atuação da Inova - Unicamp, constatou-se que aquele órgão apresenta, na prática, um processo de produção e disseminação de informação tecnológica ao levar a inovação para o setor produtivo por meio da transformação do conhecimento científico e tecnológico em resultado econômico, adotando um modelo de atuação que denominamos "modelo de produção e disseminação da informação tecnológica".

\section{A I NOVAÇÃO}

A inovação, uma tentativa criativa de adaptação às condições de mudanças deliberadas e de ambiente, resulta de um renovado interesse no aprendizado e no conhecimento que possam ser aplicados a um produto ou processo. Aquelas empresas desejosas de serem bem sucedidas em seus processos de aprendizado e de inovação deverão empenhar-se sistematicamente na criação e na utilização de novos conhecimentos e experiências, ao mesmo tempo em que procuram realizar todas suas operações a custos cada vez menores. Para
Schumpeter (1982, p. 48), a inovação, por se tratar de "novas combinações de meios produtivos" caracteriza o desenvolvimento econômico pelas realizações que se tornam necessárias para produzi-las (Schumpeter, 1982, p.48).

O processo de inovação envolve a articulação de vários agentes e fontes de informação tanto internas quanto externas. Trata-se de um processo interativo que envolve a sociedade, o governo, as empresas, as universidades e institutos de pesquisa (Lemos, 2000; Vasconcelos; Ferreira, 2000).

No Brasil, o desenvolvimento científico e tecnológico partiu basicamente de ações governamentais. Como resultado dessa política, o desenvolvimento científico e tecnológico ficou desvinculado do setor privado e ganhou o status de assunto acadêmico.

Na academia, como afirma Cruz (2000), foi priorizada a pesquisa básica e fundamental, mais desinteressada de resultados imediatos, sigilo e preocupações como aplicabilidade e retorno, questões mais afeitas às empresas.

Com poucos cientistas e engenheiros atuando em P\&D no Brasil, há um percentual muito reduzido dos que trabalham para empresas. Para Cruz (2000), o grande desafio em P\&D atual no Brasil é a criação de um ambiente que estimule a empresa a investir no conhecimento para aumentar sua competitividade.

De acordo com o Livro Branco da Ciência, Tecnologia e Inovação (Brasil, 2002, p.27):

Mesmo ao se realçar o papel central da empresa como motor da inovação, não se deve omitir que esse processo é produto de um conjunto de habilidades coletivas muito mais amplas, canalizadas para gerar, absorver e difundir o novo. Poder inovar exige mais que saber produzir: demanda conhecimento para projetar novas tecnologias de produtos ou de processos; envolve a realização de atividades de pesquisa e desenvolvimento nas empresas, internamente ou em cooperação com outros agentes; a importação e absorção de tecnologias; a formação de pessoas qualificadas para a inovação e sua fixação nas empresas; e, a disponibilidade de infra-estrutura científica e tecnológica. 
A contribuição fundamental dos institutos, das universidades e do Estado seria o de promover o desenvolvimento da infra-estrutura de serviços tecnológicos de apoio à inovação e competitividade, tais como a modernização das regulamentações técnicas e avaliação de conformidade; o apoio à homologação, certificação, metrologia e normalização; as pesquisas de novas tecnologias de gestão; o auxílio na proteção da propriedade intelectual e a disseminação efetiva da informação tecnológica.

Apesar de alguns esforços governamentais e das iniciativas de algumas instituições de ensino e pesquisa, a infra-estrutura necessária à sistematização da informação ainda depende de investimentos maciços. Somando-se isso à pouca compreensão por parte do empresariado do valor que as informações geradas pela pesquisa científica podem ter, pode-se entender melhor o quanto ainda é necessário ser feito para mudar o quadro atual da disponibilização de informação tecnológica no Brasil (Valentim, 2002).

As iniciativas da UNICAMP por meio das ações desenvolvidas em sua Agência de Inovação, a InovaUnicamp, demonstram sua preocupação em buscar um bom termo para essa questão. Por um lado a Universidade busca a formação qualificada de mãode-obra capaz de inovar - e por outro permanece promovendo a pesquisa e o avanço do conhecimento, necessários ao desenvolvimento tecnológico.

\section{A INOVA-UNICAMPE SEU CAMPO DE AÇ $\tilde{A} O$}

Criada pela RESOLUÇÃO GR N ${ }^{\circ} 51$, de 23 de julho de 2003, a Inova-Unicamp teve seu processo de institucionalização atualizado pela Deliberação CADA-2 de 12 de novembro de 2004. missão:

artigo $1^{\circ}$ dessa Deliberação estabelece sua

Fica criada a Agência de Inovação da UNICAMP - Inova-Unicamp - junto ao Gabinete do Reitor, com a missão de fortalecer as parcerias da UNICAMP com empresas, órgãos de governo e demais organizações da sociedade, criando oportunidades para que as atividades de ensino e pesquisa se beneficiem dessas interações e contribuindo para o desenvolvimento econômico e social do País (UNICAMP, 2004, p. 1).

Com um leque de atuação bastante abrangente, a Inova-Unicamp busca o estreitamento do relacionamento da universidade com a sociedade, estimulando parcerias com empresas, setor público, institutos e fundações (INOVA-UNICAMP, 2006).

Essas parcerias envolvem:

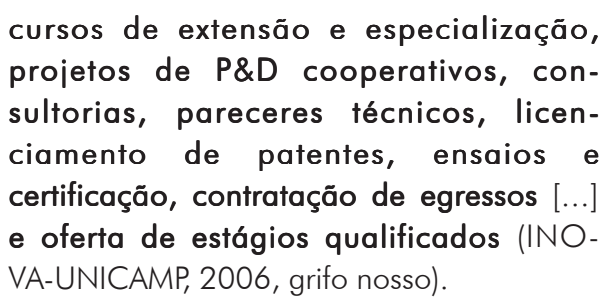

Tais ações de parceria pretendem "facilitar o acesso das empresas e dos órgãos públicos às atividades que a universidade realiza ou pode realizar", procurando tornar esse relacionamento mais efetivo para todos, estimulando a apresentação de demandas e identificando novas oportunidades de interesse comum (INOVA-UNICAMP, 2006).

O interesse por convênios de cooperação e/ou parcerias universidade-empresa tem sido despertado pela crescente competitividade que tem levado as empresas a buscar o desenvolvimento de novas tecnologias. Porém, devido ao alto custo e risco envolvidos na implantação de laboratórios de pesquisa e contratação de mão de obra qualificada, passam a buscar apoio onde a maior parte dos recursos necessários provêm de recursos públicos: em centros de tecnologia ou universidades públicas (Galbraith, 1977, p. 19; INOVA-UNICAMP, 2006).

Com a finalidade de proteger a propriedade intelectual das tecnologias, marcas, produtos, ou processos desenvolvidos na UNICAMP, a Agência de Inovação auxilia os pesquisadores da universidade nos procedimentos de registro de propriedade intelectual das invenções, nos processos de licenciamento das inovações, na redação e depósito da patente, no registro de software, na identificação de produtos ou processos patenteáveis e licenciáveis (INOVA-UNICAMP, 2006).

Essas ações, além de prevenir "de que competidores copiem e vendam esse produto a um preço mais baixo, uma vez que eles não foram onerados com 
os custos da pesquisa e desenvolvimento do produto", pretendem gerar "oportunidades de licenciamento e de parcerias com empresas" e "estimular as atividades de pesquisa da universidade" (INOVA-UNICAMP, 2006; INPI, 2006).

Outra atividade de parceria da Inova-Unicamp é o projeto "Inova nos Municípios" - uma estratégia de relacionamento com as prefeituras dos municípios do Estado de São Paulo, por meio do intercâmbio de informações a fim de tornar pública toda a gama de projetos envolvendo temas como políticas públicas, educação, cultura, governo - entre outros - que podem ser oferecidos por meio de cursos, palestras, etc, pela Universidade a municípios conveniados (INOVAUNICAMP, 2006).

Juntamente com agências de fomento governamentais e investidores privados, a InovaUnicamp busca estimular o surgimento de empresas de base tecnológica e o fortalecimento das atividades de P\&D atuando em incubação de empresas e no incentivo à implantação e o desenvolvimento do Parque Tecnológico de Campinas (INOVA-UNICAMP, 2006).

Um dos objetivos da instalação de um Parque Tecnológico é a promoção da "cultura da inovação e da competitividade", por meio de empresas "baseadas no conhecimento". Os parques funcionam como condomínios empresariais, oferecendo, além da infraestrutura adequada - tais como serviços de telemática e transportes, segurança, limpeza, manutenção, etc acesso a serviços de assessoria e consultoria às empresas instaladas (INOVA-UNICAMP, 2006).

A Inova-Unicamp também é responsável pelo Programa de Incubadoras de Base Tecnológica e incorpora as atividades de coordenação da Incubadora de Empresas de Base Tecnológica da UNICAMP (INCAMP) desde 2003, conforme a Resolução GR 051/ 2003 (UNICAMP, 2003).

A INCAMP tem como objetivos:

- Possibilitar a interação com as unidades de ensino e pesquisa da UNICAMP, para acesso às informações científicas e serviços tecnológicos;

- Apoio na identificação de pesquisadores que possam colaborar no aprimoramento tecnológico dos produtos, processos e serviços;
- Assessoria técnica para elaboração e encaminhamento de projetos para captação de recursos junto às agências de fomento;

- Assessoria técnica para apresentação e projetos a investidores em geral;

- Assessoria técnica para registro de Propriedade Intelectual;

- Assessoria técnica no processo de licenciamento de produtos junto aos órgãos governamentais;

- Orientação para elaboração e/ou atualização do plano de negócios;

- Apoio na participação em feiras e eventos pertinentes a área de atuação da empresa residente;

- Capacitação na gestão empresarial, tais como: gestão financeira, custos, marketing, planejamento, administração geral, produção e operações (INCAMP, 2006, grifos nossos).

Dentre as iniciativas da INCAMP com vistas ao fortalecimento das empresas incubadas, encontra-se a implantação de ambientes de pré-incubação de projetos.

objetivo da pré-incubação é propiciar aos candidatos a empreendedor um ambiente de relacionamento com professores, pesquisadores e mentores de mercado - profissionais que auxiliam os futuros empreendedores a avaliar a viabilidade de suas idéias antes da abertura legal da empresa. A partir desses relacionamentos e da construção de um plano de negócios embasado, os projetos podem evoluir para empreendimentos estabelecidos ou vir a ser abrigados na INCAMP.

Outro programa conduzido pela Inova-Unicamp é o PIT - Programa de Investigação Tecnológica. Sob a coordenação da Inova-Unicamp, alunos da UNICAMP conduzem avaliações e qualificação de tecnologias inovadoras pesquisadas pela universidade que se traduzam em aplicações práticas para a sociedade.

Os alunos da UNICAMP interessados no Programa são selecionados pela Inova-Unicamp e submetem-se a cursos e seminários de formação em investigação tecnológica. Passam a ser denominados 
"equipe de execução" e irão selecionar e qualificar tecnologias (INOVA-UNICAMP, 2006).

Os pesquisadores da UNICAMP que desejam que suas tecnologias sejam investigadas submetemnas a uma análise pela Inova-Unicamp, que define quais serão selecionadas, considerando-se o "potencial de aplicação e de transferência da tecnologia, estágio de desenvolvimento e aderência ao mercado" (INOVAUNICAMP, 2006).

As investigações tecnológicas são realizadas por meio de visitas aos laboratórios, buscando obter uma caracterização detalhada das tecnologias e de suas possibilidades de aderência ao mercado, por meio de estudos de viabilidade técnica e econômica. Uma vez que se identificam oportunidades viáveis, busca-se atrair investidores interessados em pequenas empresas de base tecnológica.

O SEBRAE-SP (Serviço de Apoio às Micro e Pequenas Empresas do Estado de São Paulo) participa do PIT como órgão financiador. Seu apoio demonstra o alinhamento do Programa às experiências do SEBRAESP no incentivo ao empreendedorismo (INOVAUNICAMP, 2006).

O PIT pretende disseminar a cultura da inovação como vetor da competitividade empresarial, não apenas estimulando os estudantes envolvidos no programa, mas também permitindo o acesso de pequenas empresas e investidores às tecnologias desenvolvidas com a parceria da Universidade e outros Centros de Pesquisa onde os alunos atuam como "fonte adicional de informações" que promoverão a melhoria de competitividade, adotando o desenvolvimento de "novas tecnologias, novos produtos e processos e melhoria das práticas de produção e gestão" como forma de "conversão de conhecimento em valor" (INOVAUNICAMP, 2006).

Espera-se que o Programa promova:

- Desenvolvimento da cultura de inovação com foco em transferência de tecnologia e/ou criação de novos negócios;

- Geração de informações qualificadas para o trabalho de promoção e negociação de novas tecnologias;

- Transformação do estoque de conhecimento da UNICAMP em riquezas para o País;
- Geração de pequenas empresas (spin-off) e atração de investimento privado para o ciclo da inovação: do laboratório ao mercado;

- Fortalecimento do Arranjo Produtivo Local, incentivando o uso de novas tecnologias e a criação de novas empresas;

- Servir de programa piloto a ser reproduzido pelas instituições de ensino e pesquisa associadas à Fundação Fórum Campinas, no Estado de São Paulo e no Brasil (INOVA-UNICAMP, 2006, grifos nossos).

As atividades desenvolvidas pelo PIT:

[...] servem de suporte para a atuação da Inova-Unicamp como agente difusor das tecnologias geradas na UNICAMP. A interface direta com os pesquisadores para a realização das investigações tecnológicas, potencializada pelo número de agentes participantes do Programa, acelera o processo de transferência do conhecimento para a sociedade (INOVA-UNICAMP, 2006, grifos nossos).

Para atender aos projetos de pesquisa e desenvolvimento de tecnologias da informação (TI), em parceria com a lnova-Unicamp e unidades da Unicamp, está sendo criada a lnovasoft, um centro de incubação e pré-incubação de projetos de $\mathrm{TI}$. $\bigcirc$ projeto será regulamentado por uma Resolução do Gabinete do Reitor e será fisicamente alocado no prédio onde atualmente se aloja o Núcleo Softex Campinas (INOVAUNICAMP, 2006).

No setor cultural a Inova-Unicamp possui uma atuação bastante expressiva em parceria com o Instituto de Artes e outras unidades da Unicamp na busca de financiamento para projetos artísticos e culturais. Esse apoio se dá por meio da assessoria aos professores na elaboração, encaminhamento e acompanhamento de propostas ao Ministério da Cultura para seu enquadramento na Lei Rouanet (lei de incentivo à cultura).

Para propiciar um maior número de oportunidades de interação da universidade com as empresas e atrair sua participação em seus projetos a Inova-Unicamp, possui um programa chamado "Workshops" de Parceria. 
Os "Workshops" promovem a troca de experiências sobre a produção científica e tecnológica da universidade, convidando pesquisadores e executivos de empresas dos mais diversos portes, nacionais e multinacionais, na expectativa de criar um espaço facilitador entre a universidade e as empresas que se transformem em futuros projetos de pesquisa conjunta, acesso à tecnologia da universidade, ou geração de patentes e consórcios de pesquisa cooperativa. Trata-se de uma das interfaces de relacionamento direto com as empresas, aspecto fundamental dos processos de transferência de tecnologia e de interação universidade-sociedade.

A partir da experiência adquirida na realização dos "Workshops" de Parceria, a Agência de Inovação da Unicamp desenvolveu o Projeto C4P (Caderno de Propostas de Projetos de Pesquisa para Parceria).

Com base em uma proposta de projeto de pesquisa e o desejo de encontrar um parceiro para desenvolvimento conjunto, esse caderno age como veículo para sua divulgação.

O C4P - Inova tem três eixos de atuação:

- Coleta de projetos de pesquisa de professores e pesquisadores da Unicamp nas áreas de ciências humanas, exatas, ciências da vida e tecnologia;

- Agrupamento das propostas no Caderno de Propostas de Projetos de Pesquisa para Parcerias e,

- Divulgação do Caderno por via eletrônica ("site" da Inova).

As propostas são apresentadas sucintamente e tem como autor principal um professor/pesquisador da Unicamp que as submetem preenchendo um formulário próprio disponível no "site" da Inova (www.inova.unicamp.br).

A Inova-Unicamp ainda organiza eventos, cursos, exposições e apresentações das suas atividades como forma de estimular o relacionamento universidadeempresa, destacar a importância da criação e fortalecimento de empresas de base tecnológica e divulgar a política de propriedade intelectual para a comunidade interna da UNICAMP.

\section{RESULTADOS DOESTUDO DE CASO}

O estudo de caso da Agência Inova-Unicamp estruturou-se em quatro pilares de observação:

\section{O processo de sistematização da produção do conhecimento científico e tecnológico da UNICAMP}

O processo de sistematização da produção do conhecimento científico e tecnológico ocorre quando a Inova-Unicamp auxilia os pesquisadores nas tarefas de registro de patentes, no licenciamento de tecnologias ou na formulação de contratos de transferência de tecnologia, seja para o repasse de um conhecimento explícito (um know-how) ou quando o pesquisador irá prestar serviços a determinada empresa por possuir o conhecimento tácito de como atingir os objetivos de determinado experimento.

Os pesquisadores procuram a Inova-Unicamp, que envia técnicos especializados que irão recolher as informações. Assim que as analisam, preparam os documentos necessários ao encaminhamento para as soluções que irão atendê-los: registro de patente junto ao INPI, licenciamento de tecnologia, contratos de prestação de serviços ou outras no escopo de atuação da Agência.

Em função do grande número de atividades em que atua, a Inova-Unicamp possui alguns contratos de terceirização. No caso da propriedade intelectual, escritórios especializados em marcas e patentes foram contratados como auxiliares nas tarefas de levantamento da documentação necessária e registro. A InovaUnicamp atua como fiscalizadora da qualidade dos serviços executados. Após todos os trâmites legais e tendo sido a patente registrada, ela é disponibilizada em um banco de patentes na página da Internet da Inova-Unicamp.

A experiência acumulada pela UNICAMP em relação à Ciência, Tecnologia e Inovação tem relação com seu histórico de universidade sempre voltada à tecnologia. De acordo com os entrevistados, o processo de sistematização da produção de conhecimento na universidade é bastante anterior ao surgimento da Inova-Unicamp, uma vez que já era feito pelo Escritório de Transferência de Tecnologia (ETT) criado em 1990 e sucedido pelo Escritório de Difusão e Serviços Tecnológicos (EDISTEC), serviço criado em 1998. Em 2003, o EDISTEC teve suas atividades, instalações e funcionários transferidos para a Inova-Unicamp, o que garantiu a absorção da experiência acumulada pelos participantes na constituição do perfil que a Agência possui hoje. 


\section{O processo de disseminação da informação tecnológica}

Uma característica apontada pelo estudo foi a postura da Agência Inova buscar dentre a produção científica da universidade, o que se levanta de necessidade por parte das empresas.

Segundo a cartilha do PACTI (1992), os instrumentos para o desenvolvimento tecnológico são classificados em dois conceitos: "instrumentos orientados pelo mercado - demand pull" e "instrumentos orientados pela tecnologia technology push" (PACTI, 1992, p.7- 8).

A atitude adotada pela Inova-Unicamp foi a de mesclar os dois conceitos. Age de modo demand pull quando procura o que a Unicamp produz, analisandose o que se tem de demanda, levantadas por meio de seus contatos com as empresas e workshops de parceria. Age de modo technology push quando monta porttólios, ou apresenta para as empresas, ou associações de empresas, as patentes geradas na Universidade para que elas verifiquem se ali há alguma produção científica de interesse daquela indústria.

Seu processo de disseminação da informação tecnológica ocorre por meio dos cursos, "workshops" de parceria, eventos e principalmente por meio da divulgação de suas patentes. Assim o registro de patentes torna-se um importante documento, tangível para a disseminação da informação tecnológica pela Inova-Unicamp, propiciando a aproximação da universidade com a sociedade, favorecendo o desenvolvimento tecnológico.

Como responsável pela gestão da propriedade intelectual da UNICAMP, a Inova-Unicamp detém o histórico da universidade em seus pedidos de patente. São 468 pedidos de patente depositados de 1989 até junho de 2006, além de 56 marcas e 62 softwares. Todas as patentes ficam disponíveis no banco de patentes da Inova-Unicamp na Internet.

O número de pedidos de depósitos de patentes por ano tem apresentado um aumento significativo. Segundo o jornal O Estado de São Paulo, de 16.05.2006 a UNICAMP superou, pela primeira vez, a Petrobrás, em número de patentes registradas no INPI este ano (Sant'anna, 2006).

O número elevado de patentes que se tem alcançado nos anos mais recentes é fruto da postura da UNICAMP em relação à proteção e a valorização do conhecimento gerado. $O$ conceito de que nenhuma empresa se interessa por uma tecnologia que não está protegida - que não tem reserva de mercado - e de que isso a impede de ser utilizada pela sociedade, passou a ser melhor compreendido no meio universitário. A patente, ao mesmo tempo em que permite a disseminação, também protege a tecnologia.

A disponibilização da grande maioria das informações a respeito da Inova-Unicamp e suas atividades - incluindo aí o seu banco de dados de patentes na Internet - surgiu com a intenção de facilitar o acesso à informação necessária sobre patentes e outros conhecimentos da Universidade.

As barreiras de linguagem e de comunicação entre o meio acadêmico e o meio empresarial têm sido contornadas por meio de pessoas mais bem treinadas para compreender as diferenças de interesse das duas partes, para destacar a credibilidade e a seriedade da Universidade, e também para estimular a pré-disposição do mercado, uma vez que as empresas têm-se conscientizado, cada vez mais, da importância da pesquisa e da inovação.

Tecnologias desenvolvidas e licenciadas pela UNICAMP passaram a ser divulgadas em jornais de negócios, o que atraiu muitas empresas para conhecer o trabalho desenvolvido pela Universidade e pela InovaUnicamp.

Segundo a Inova-Unicamp, a UNICAMP alcançou nos últimos anos a condição de universidade de referência na pesquisa científica e no desenvolvimento de tecnologias para os setores de produção de bens e serviços: é a universidade brasileira que mantêm mais vínculos com esses setores, sinal de sua maior aproximação com as empresas. Somente nos últimos três anos foram firmados mais de 250 contratos de serviços e de repasse tecnológico com o meio empresarial (INOVA-UNICAMP, 2006).

\section{Características da informação tecnológica desenvolvida e disseminada pela Inova-Unicamp}

A informação tecnológica desenvolvida e disseminada na UNICAMP, por meio da InovaUnicamp, tem como característica principal a inovação. 
A Inova-Unicamp trabalha como um serviço de interface de informações estritamente ligadas ao processo inovador, estimulando essas importantes transformações nas indústrias. A agência segue o postulado schumpeteriano de acreditar que a inovação só se manifesta quando foi assimilada pelo mercado; caso contrário, é apenas invenção (Schumpeter, 1982, p.62).

Nesse sentido, a proteção intelectual do conhecimento é um processo extremamente importante, porém de menor alcance. Existe a percepção na InovaUnicamp de que o processo não deve se encerrar aí, ou seja, deve haver a possibilidade não somente de transferência do conhecimento à sociedade como também de geração de valor econômico.

A Inova-Unicamp procura realizar outras formas de transferência de informação tecnológica, além do licenciamento de patentes. A transferência de tecnologia é vista como um processo maior, no qual o licenciamento é apenas uma parte.

Oestímulo à geração de empresas nascentes, por meio das atividades de incubação e pré-incubação - que carregam tanto a tecnologia absorvida no contato diário com pesquisas e pesquisadores para o mercado quanto o enriquecimento na formação dos alunos, colocando-os em contato com as tecnologias de ponta -, é uma outra forma de transferir informação tecnológica.

A informação tecnológica pode também estar presente de forma tácita. Várias tecnologias descritas ou exploradas apenas teoricamente, publicadas por meio de artigos ou teses, são formas de transferência de informação tecnológica. Ciente do valor do conhecimento tácito nos processos de produção do conhecimento, a Inova-Unicamp não despreza as possibilidades de atender as necessidades das empresas também nesse sentido.

Nesses casos, pode haver a contratação do "conhecimento" do pesquisador, em forma de consultoria, pois, sem seu acompanhamento, pode não haver sucesso na implantação de um processo criado em decorrência de seus estudos.

Esse tipo de necessidade, quando ocorre, é resolvida com a contratação dos serviços do pesquisador por meio da FUNCAMP.

\section{Público consumidor da informação disponibilizada pela Inova-Unicamp.}

público consumidor da informação disponibilizada pela Inova-Unicamp, nesta pesquisa, foi identificado como sendo: os estudantes envolvidos nas atividades de pesquisa, os pesquisadores, os representantes das empresas demandantes de tecnologia, os dirigentes das empresas incubadas, as empresas de base tecnológica interessadas em instalarse no parque tecnológico de Campinas e, finalmente, a sociedade como um todo, quando recebe os benefícios das informações agregadas às novas tecnologias desenvolvidas.

\section{- Pesquisadores e estudantes:}

Quando um pesquisador desenvolve um novo produto ou busca uma melhoria de processo, gera dois tipos de benefício: os diretos, de características de curto prazo, ligados diretamente ao produto ou processo em estudo e os estruturais ou indiretos que, mais ligados ao ensino, terão efeitos produzidos e percebidos em longo prazo, pois impactam os estudantes e seus conhecimentos. Tal fato ocorre nas várias oportunidades em que há o envolvimento direto dos estudantes nas atividades de pesquisa, ou quando o pesquisador leva para a sala de aula os resultados de seus trabalhos.

Outro Programa que incentiva a participação de pesquisadores e estudantes é o Programa de Investigação Tecnológica (PIT). Desde sua implantação, 60 projetos já foram desenvolvidos no PIT, no qual a parte de investigação é conduzida por alunos da UNICAMP que, ao acompanharem de perto as pesquisas de ponta surgidas na universidade, despertam suas próprias potencialidades.

$\mathrm{Na}$ página da Inova-Unicamp na internet (http://www.inova.unicamp.br) é possível consultar todos os projetos, onde constam: nome do professor; unidade; título do projeto; númeo da patente, agente da investigação e situação em dez/ 2005.

\section{- As empresas demandantes de tecnologia:}

Uma avaliação que pode ser feita em relação ao público consumidor da informação é por meio dos 
licenciamentos celebrados entre a UNICAMP e as empresas. Distribuídos por setor de atividade, demonstram que tipo de pesquisas têm tido maior procura por licenciamento na UNICAMP (Figura 1).

Verifica-se que os setores de fármacos (37\%) e química (18\%) apresentam-se como os dois primeiros mais procurados, seguidos (todas empatadas em 9\%) dos setores de: agribusiness e meio ambiente, fitoterápico, médico e optoeletrônica.
Apesar de existirem patentes disponíveis para outros setores (como, por exemplo, o de alimentos, telecomunicações e produtos de consumo), ainda não ocorreram licenciamentos.

Não há nos registros da Inova-Unicamp uma classificação por tamanho ou porte da empresa que a procura; as solicitações são analisadas e atendidas conforme estejam adequadas à sua missão. Nota-se que não há privilégios quanto ao tamanho dos

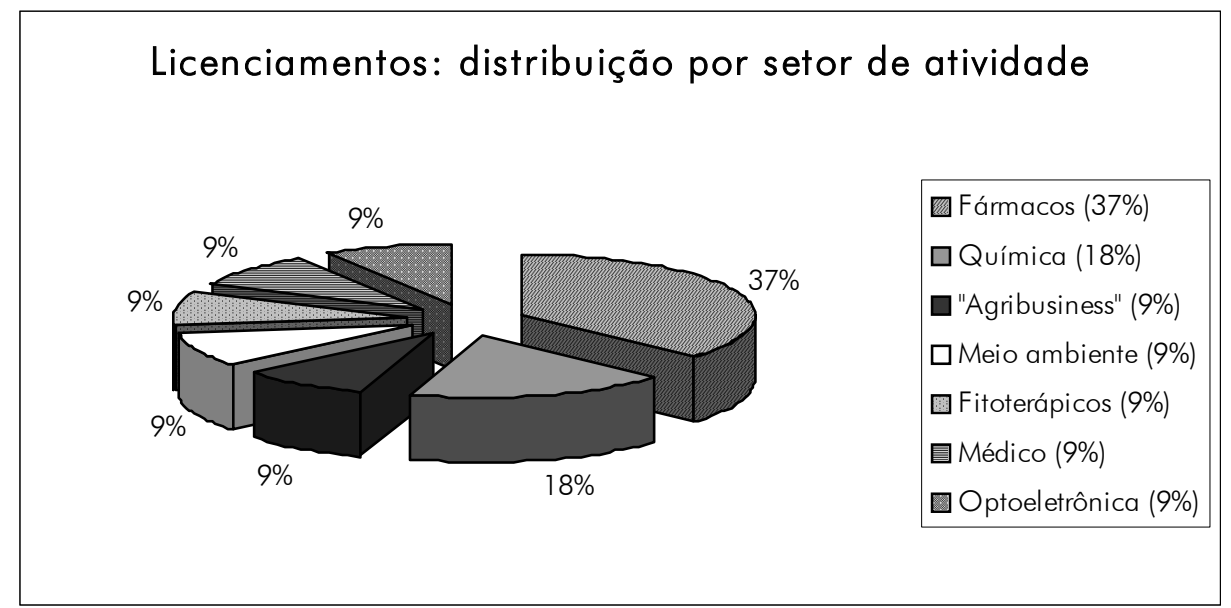

Figura 1. Licenciamentos: distribuição por setor de atividade.

Fonte: Baseado em informações fornecidas pela INOVA-UNICAMP (2006).

contratos em função de seus valores financeiros. Mesmo que os "contratos assinados sejam de pequeno valor inicial, existem possibilidades de crescimento em função de um bom projeto em parceria" (INOVA-UNICAMP, 2006).

Uma de suas políticas, porém, é a de "procurar parceiros com potencial de colaborar em projetos que sejam estruturantes e de grande valor científico". No Gráfico 3 (abaixo) pode-se visualizar a distribuição do número de contratos em função de seus valores no ano de 2005.

Os contratos mais assinados (em escala de valores), em primeiro lugar aqueles situados entre dez mil e cinqüenta mil reais $(39,29 \%)$, seguido dos contratos entre duzentos mil e um milhão de reais $(35,71 \%)$, estando em terceiro lugar os contratos entre cinqüenta mil e duzentos mil reais $(10,71 \%)$, e empatados em último lugar os contratos até dez mil reais $(7,14 \%)$ e os acima de um milhão de reais $(7,14 \%)$.
- As empresas incubadas:

O estímulo da INCAMP a empresas nascentes representa claramente a intenção da Inova-Unicamp de levar informação às empresas de qualquer porte. A Inova-Unicamp já criou as condições para o surgimento de vários empreendimentos criados por alunos, exalunos e ex-pesquisadores da UNICAMP, sendo muitos destes negócios reconhecidamente bem sucedidos. Segundo a Inova-Unicamp, isso ocorre em função de já haver se estabelecido na UNICAMP uma cultura de empreendedorismo. Nas últimas duas décadas, pelo menos 89 empresas nasceram a partir das salas de aula da universidade. Juntas, as "empresas filhas" da UNICAMP já respondem por faturamento da ordem de R\$ 700 milhões por ano, o que representa 7\% do Produto Interno Bruto (PIB) gerado no município de Campinas (INOVA-UNICAMP, 2006).

Na INCAMP, atualmente, estão abrigadas 12 empresas incubadas, das quais 9 estão nas instalações 
da incubadora e 3 ocupam espaços dentro de outras unidades da UNICAMP.

\section{- As empresas de base tecnológica interessadas no Parque Tecnológico de Campinas:}

Uma outra forma de estimular o surgimento de novos negócios e passar a atender um público de usuários ainda maior é por meio da participação da Inova-Unicamp no incentivo à criação de Parques Tecnológicos.

O Sistema Paulista de Parques Tecnológicos foi criado pelo Governo do Estado e teve sua publicação no Diário Oficial do Estado de São Paulo no dia 07.02.2006. Os parques tecnológicos, segundo o decreto, consistem em empreendimentos criados e geridos com o objetivo permanente de promover a pesquisa e a inovação tecnológicas e dar suporte ao desenvolvimento de atividades empresariais intensivas em conhecimento (São Paulo, 2006).

A proposta do governo paulista define quais pólos regionais sediarão parques científicos e tecnológicos e aloca investimentos significativos para essa finalidade. Campinas foi um dos municípios escolhidos para abrigar um dos cinco pólos definidos pelo Estado. O projeto de Campinas foi o primeiro a ficar pronto, e, para isso, foi fundamental o trabalho da Inova-Unicamp, que centraliza as ações de organização do novo parque. O estudo desenvolvido pela Inova-Unicamp inclui um Plano de Desenvolvimento Básico (PDB), que traça as diretrizes para a ocupação da área de forma articulada com o planejamento urbano da cidade, preservando recursos naturais e definindo propostas que resultem na criação de um empreendimento sustentável do ponto de vista ambiental.

O parque de Campinas está previsto para ocupar uma área de aproximadamente 8 milhões de metros quadrados, numa região que faz limite com a UNICAMP, a PUC-Campinas e a rodovia CampinasMogi Mirim e onde já estão em funcionamento empresas e instituições de base tecnológica, como por exemplo, - $\mathrm{CPqD}$ e o Laboratório Nacional de Luz Síncrotron (INOVA-UNICAMP, 2006).

\section{- A sociedade como um todo:}

Além de todas as oportunidades que podem ser geradas a partir das iniciativas na área de tecnologia produzidas pela universidade e que beneficiam a sociedade como um todo, outras áreas do conhecimento não foram esquecidas.

O encaminhamento de projetos culturais ao Ministério da Cultura é outra atividade que a InovaUnicamp está realizando. Com isso, o público atendido pelas informações da Inova-Unicamp estender-se-á àqueles envolvidos com as áreas responsáveis por projetos culturais da UNICAMP e indiretamente beneficiar-se-ão os que assistirem a peças de teatro, visitarem museus ou tiverem acesso a algum livro ou obra de arte.

\section{A ATUAÇ ÃO DA INO VA-UNICAMP}

No Brasil existem vários tipos de núcleo de inovação, ou departamentos relacionados à inovação, pertencentes a universidades. Muitas delas, tal como a Inova-Unicamp, têm a responsabilidade de fazer o relacionamento universidade-empresa.

A ałuação da Inova-Unicamp é caracterizada por uma série de particularidades: o planejamento estratégico que a definiu como pró-ativa, sua forma de relacionamento com os pesquisadores e as atividades que teria que desenvolver paralelamente ao trabalho de proteção da propriedade intelectual, como a incubadora e o desenvolvimento de parcerias.

Ao investigar quais conhecimentos a UNICAMP está buscando adquirir, que se traduzam em inovações, a Inova-Unicamp age como intermediadora da informação.

Na Inova-Unicamp, o processo de inovação não é entendido por meio de um modelo linear ou seqüencial.

No modelo linear, o desenvolvimento, a produção e a comercialização de novas tecnologias são vistos como uma seqüência de tempo bem definida, que se origina nas atividades de pesquisa, envolvidas na fase de desenvolvimento do produto e leva à produção e, eventualmente, à comercialização. [...] $\bigcirc$ modelo, sustentado pelas teorias clássica e neoclássica, passou a ser considerado superado por se apoiar excessivamente na pesquisa científica como fonte de novas tecnologias, além de implicar em uma abordagem seqüencial - descoberta científica, 
invenção, industrialização e mercado (Grizendi, 2006, p. 1).

Dessa forma, a Inova-Unicamp percebe as relações da pesquisa com a inovação por meio de um modelo que considera o processo de inovação interativo e multidirecional - o chamado "modelo interativo", em que as necessidades de informação e os conhecimentos gerados dependem fortemente de quanta resposta ou feed-back todo o sistema envolvido consegue gerar nas constantes interfaces ocorridas entre todos os componentes - mercado potencial, pesquisadores, conhecimento, etc. (Grizendi, 2006).

Quanto ao modelo de gestão adotado pela Inova-Unicamp, em resposta obtida durante a fase de entrevista, existem três modelos de atuação para uma agência de inovação: o modelo legal, o modelo administrativo e o modelo de comercialização. Essas definições apresentam-se amplamente difundidas entre os colaboradores da Agência.

Segundo tais definições, o modelo legal é aquele que interpreta as relações universidade-empresa como um processo legal, ocupando-se na maior parte do tempo dos aspectos jurídicos da relação entre as instituições.

modelo administrativo é aquele que cuida mais dos aspectos formais de assinatura de convênio, cuidando de todos os trâmites administrativos e jurídicos, dando ênfase à necessidade do preenchimento de formulários e ao cumprimento de normas, prazos, assinaturas e outros aspectos burocráticos.

modelo de comercialização, no qual os entrevistados afirmam encontrar-se a Inova-Unicamp, é o modelo que usa práticas de negociação e gestão empresarial. Baseado em um escritório independente do processo decisório, possui uma visão de gestão que considera sua auto-sustentabilidade financeira, o cumprimento de metas e atingimento de resultados (por meio de indicadores), e que prioriza o trabalho em parceria com os pesquisadores.

Ainda segundo os entrevistados, apesar de vários modelos de atuação que se poderiam adotar, optou-se por aquele que fosse mais pró-ativo, constituído por uma equipe mista possuidora de um perfil equilibrado entre a experiência acadêmica e a formação comercial e que soubesse valorizar os pesquisadores, demonstrando que o órgão não é decisório, não é hierárquico, e nem se trata de uma unidade de pesquisa. Tal postura visa à promoção da confiança do pesquisador no trabalho da Agência deixando clara sua função como organismo articulador de parcerias.

\section{A MATERIALIZAÇÃO DO CONCEITO DE INFORMAÇÃO TECNOLÓGICA}

fato de o país ter atualmente maior acesso às tecnologias de informação e comunicação não resolve a questão da coleta, tratamento e disponibilização adequada de informações, tampouco as informações tecnológicas. Para que a informação tecnológica possa ser utilizada como recurso técnico que permita a criação de novas estruturas industriais, em bases mais competitivas, é necessário buscar soluções para o problema do desconhecimento, por parte dos atores envolvidos, da importância e da necessidade em melhor utilizar as fontes de informação disponíveis.

É preciso insistir nos processos de criação de cultura empreendedora e de capacitação, assim como a Inova-Unicamp está fazendo em seus Projetos de Incubação, Pré-incubação, Programa de Investigação Tecnológica, Desenvolvimento de Parques Tecnológicos, Workshops de Parceria, etc. Seus estudos e atividades promovem a aproximação da universidade com a iniciativa privada e pretendem produzir avanços no cenário da inovação que se reflitam positivamente no desenvolvimento da ciência e tecnologia - peça-chave na competitividade do país.

que se pode destacar na atuação da InovaUnicamp é que os aspectos relacionados à linguagem entre duas culturas tão diversas quanto são os ambientes acadêmico e empresarial, estão sendo percebidos como barreiras e enfrentados de maneira pró-ativa. Os envolvidos no processo de tornar a comunicação efetiva, que possibilitam a transferência de informação, percebem que há a necessidade de compreender os dois códigos. Na Inova-Unicamp, essa habilidade está sendo chamada de "conhecer a linguagem do mercado".

Suas ações efetivas nos processos de registro dos conhecimentos, quando, por exemplo, faz a gestão da propriedade intelectual - atividade em que tem que se relacionar com o ambiente acadêmico -, e nos processos de disseminação, quando alcança as empresas em seus "workshops" e posteriormente celebra 
contratos de licenciamento - momento em que se relaciona com as empresas -, demonstram sua capacidade em transpor algumas dessas barreiras.

Um dos objetivos da Inova-Unicamp, identificado no estudo, é o de que o relacionamento com as empresas traga como um de seus maiores benefícios não somente os royalties pagos e sim maiores oportunidades para o ensino e a pesquisa da UNICAMP, motivando o trabalho dos professores pesquisadores e aproximando o corpo discente das fronteiras da inovação. É por meio da formação de alunos familiarizados com os modernos métodos de pesquisa e impelidos à inovação e ao empreendedorismo que a Inova-Unicamp realiza sua maior contribuição para a sociedade.

Esses aspectos todos somados é que constituíram a credibilidade da Inova-Unicamp, tanto interna quanto externamente.

Em nossa análise, considerando-se não apenas os modelos em que a própria Agência, por meio de seus membros se define, os quais são o "modelo interativo" de compreensão do processo de inovação e o "modelo de comercialização", como também o seu interesse fundamental de "melhorar o ensino e a pesquisa", seu alinhamento com a conceituação de informação tecnológica e sua postura pró-ativa; poderse-ia adotar uma nova nomenclatura que a defina.

Ao modelo de atuação da Agência de Inovação da Unicamp, denominaríamos modelo de produção e disseminação da informação, principalmente em função da Inova-Unicamp, mesmo não tendo sido

\section{REFERÊNCIAS}

BRASIL. Livro branco da Ciência, Tecnologia e Inovação. Brasília: Ministério da Ciência e Tecnologia, 2002. 80p.

CRUZ, C.H.B. A universidade, a empresa e a pesquisa que o país precisa. Parcerias Estratégicas, n.8, p.5-30, 2000.

GALBRAITH, J.K. O novo estado industrial. 2.ed. São Paulo: Pioneira, 1977.

GRIZENDI, E. Processos de inovação. Campinas: Instituto Inovação, 2006. Disponível em: <www.institutoinovacao.com.br>. Acesso em: 10 jul. 2006. criada com este intuito, atender integralmente o conceito de informação tecnológica tal qual foi elaborado por Montalli e Campello (1997, p.322), que assim a definem:

\section{[...] aquela que trata da informação necessária, utilizada e da informação gerada, nos procedimentos de aquisição, inovação e transferência de tecnologia, nos procedimentos de metrologia, certificação da qualidade e normalização e nos processos de produção (grifo nosso).}

Assim cumprem-se, com este artigo, ao menos dois objetivos: o de demonstrar um modelo conceitual de informação tecnológica por meio de um exemplo prático e o de sugerir à Inova-Unicamp não apenas uma nova denominação para o que já se vem sendo feito - por meio de seus mecanismos de produção e disseminação de informação tecnológica - mas ainda um posicionamento conceitual mais alinhado ao que vem sendo realizado na Agência.

Quiçá outros serviços de informação tecnológica - não se prendendo a atuações passivas e distanciadas do conceito de informação tecnológica - passem a considerar a série de ações tomadas pelos Programas da Inova-Unicamp e venham a apresentar maiores resultados. $\bigcirc$ país agradece.
INCAMP. O que é a Incamp. 2006. Disponível em: <http:// www.incamp.unicamp.br/>. Acesso em: 10 jan. 2006.

INOVA - UNICAMP. Agência de Inovação da Unicamp. 2006. Disponível em: <hHtp://www.inova.unicamp.br>. Acesso em: 10 jan. 2006.

INPI. O que é patente? 2006. Disponível em: <http:// www.inpi.gov.br>. Acesso em: 19 mar. 2006.

LEMOS, C. Inovação na era do conhecimento. Parcerias estratégicas, n.8, p.157-179, 2000. 
MONTALLI, K.M.L.; CAMPELLO, B.S. Fontes de informação sobre companhias e produtos industriais: uma revisão de literatura. Ciência da Informação, v.26, n.3, p.321-326, 1997.

PACTI. Programas mobilizadores. Brasília: PACTI - Programa de Apoio à Capacitação Tecnológica da Indústria, 1992. 47p.

SANT'ANNA, E. Unicamp supera Petrobrás em número de patentes. O Estado de São Paulo, Campinas, 18 maio 2006.

SÃO PAULO (ESTADO). Decreto $n^{\circ}$ 50.504. Institui o Sistema Paulista de Parques Tecnológicos e dá providências correlatas. Decreto $n^{\circ} 50.504$ de 6 de fevereiro de 2006, São Paulo, SP, p. 1 3, 6 fev. 2006.

SCHUMPETER, J.A. Teoria do desenvolvimento econômico. São Paulo: Abril Cultural, 1982.
UNICAMP. Deliberação da Câmara de Administração. Dispõe sobre a criação da Agência de Inovação da Unicamp - Inova. Deliberação CAD-A-2, de 12-1 1-2004, Campinas, p. 1-3, 2004.

UNICAMP. Resolução do Gabinete do Reitor. Cria a agência de Inovação da Unicamp. Resolução GR N ${ }^{\circ}$ 51, de 23-7-2003, Campinas, p. 1-3, 2003.

VALENTIM, M.L.P. Informação em ciência e tecnologia: políticas, programas e ações governamentais - uma revisão de literatura. Ciência da Informação, v.31 , n.3, p.92-102, 2002.

VASCONCELOS, M.C.R.L.; FERREIRA, M.A.T. A contribuição da cooperação universidade-empresa para o conhecimento tecnológico da indústria. Perspectivas em Ciência da Informação, v.5, n.2, 2000. 
